\title{
Representations of Psychoactive Drugs' Use in Mass Culture and Their Impact on Audiences
}

\author{
Marek A. Motyka ${ }^{1}$ and Ahmed Al-Imam ${ }^{2,3, *(\mathbb{D})}$ \\ 1 Institute of Sociological Sciences, University of Rzeszow, 35-310 Rzeszów, Poland; mmotyka@ur.edu.pl \\ 2 Department of Anatomy and Cellular Biology, College of Medicine, University of Baghdad, \\ Baghdad 10001, Iraq \\ 3 Alumni Ambassador, Barts and the London School of Medicine and Dentistry, Queen Mary University of \\ London, London E1 2AD, UK \\ * Correspondence: ahmed.lutfi@uob.edu.iq or tesla1452@gmail.com; Tel.: +964-(0)-7714338199
}

Citation: Motyka, M.A.; Al-Imam, A. Representations of Psychoactive Drugs' Use in Mass Culture and Their Impact on Audiences. Int. J. Environ. Res. Public Health 2021, 18, 6000. https://doi.org/10.3390/ijerph18116000

Academic Editors: Eric R. Braverman Kenneth Blum, Jean Lud Cadet, Mark S. Gold and David Baron

Received: 2 May 2021

Accepted: 2 June 2021

Published: 3 June 2021

Publisher's Note: MDPI stays neutral with regard to jurisdictional claims in published maps and institutional affiliations.

Copyright: (c) 2021 by the authors. Licensee MDPI, Basel, Switzerland This article is an open access article distributed under the terms and conditions of the Creative Commons Attribution (CC BY) license (https:// creativecommons.org/licenses/by/ $4.0 /)$.

\begin{abstract}
Drug use has been increasing worldwide over recent decades. Apart from the determinants of drug initiation established in numerous studies, the authors wish to draw attention to other equally important factors, which may contribute to augmenting this phenomenon. The article aims to draw attention to the content of mass culture, especially representations of drug use in mass media, which may influence the liberalization of attitudes towards drugs and their use. The role of mass culture and its impact on the audience is discussed. It presents an overview of drug representations in the content of mass culture, e.g., in film, music, literature, and the occurrence of drug references in everyday products, e.g., food, clothes, and cosmetics. Attention was drawn to liberal attitudes of celebrities and their admissions to drug use, particularly to the impact of the presented positions on the attitudes of the audience, especially young people for whom musicians, actors, and celebrities are regarded as authorities. Indications for further preventive actions were also presented. Attention was drawn to the need to take appropriate action due to the time of the COVID-19 pandemic when many people staying at home (due to lockdown or quarantine) have the possibility of much more frequent contact with mass culture content, which may distort the image of drugs.
\end{abstract}

Keywords: mass culture; alcohol; marijuana; illegal drugs; youth; COVID-19

\section{Introduction}

Drug use data published in 2020 by the United Nations indicate that drug use is increasing worldwide, both in terms of the total number and percentage of the global drug-using population. Over the last decade (2009 to 2018), the estimated proportion of drug users increased from 210 to 269 million users (4.8\% to $5.3 \%$ of the global population). In 2017, 585,000 deaths globally were attributed to drug use due to premature death related to consequences of use and overdose [1]. The European Monitoring Centre for Drugs and Drug Addiction (EMCDDA) highlighted the high availability of drugs, especially cannabis, hashish, cocaine, and heroin. EMCDDA found that in European Union countries, more than 8300 Europeans died from drug abuse during the survey year, with an average age of about 41 years. In addition, despite the preventive measures taken (e.g., the monitoring and early warning system in EMCDDA), the introduction of new synthetic opioids on the drug market is a worrying example of the continued adaptability of producers and traffickers of these drugs [2].

Predictors of drug initiation and use tend to be similar in different parts of the world. The most commonly reported are; low parental support, upbringing in a dysfunctional family (poverty, violence, addictions, crime, and educational inefficiency), peer influences, deficits in social problem-solving skills, early exposure to tobacco influencing the initiation of marijuana experimentation, promotion of casual attitudes towards drugs by pop culture idols, low economic status, low religiosity, weakened family relationships and lack of 
parental control, weak social support network, availability of drugs, and lack of knowledge about the dangers of their use [3-7].

It is highly likely that the increase in the use of cannabis, tranquilizers, and other drugs observed in the last year results from the need to reduce the stress associated with the coronavirus pandemic [8-10]. The pandemic not only forces millions of people into long-term confinement in their homes (due to lockdown, quarantine, and fear of infection) but, above all, increases tension and its long-term impact [11]. Due to the difficulty of using numerous natural methods to reduce tension (e.g., activity, work, and sport), many people try to seek solace in psychoactive drugs $[9,12]$. Studies indicate that alcohol consumption and other recreational drugs have increased significantly since the onset of the pandemic [13].

There may also be other reasons for the popularity of psychoactive drugs. In recent years, the use of snus (a smokeless tobacco product) has become increasingly common, and chewing it is sometimes advertised as an alternative to smoking to help smokers break their addiction [14]. The promotion of new substance use runs the risk of distorting the risks associated with its use, which, while they may be less, need to be communicated. However, intrusive advertising through various means, including sending free samples to potential customers, can influence the willingness to try these new, seemingly harmless substances [15]. Comparing agents with relatively milder psychoactive effects (e.g., snus, e-cigarettes, marijuana, and even energy drinks) with drugs that cause deep physical and psychological dependence (e.g., heroin, amphetamines, and cocaine) distorts the risks associated with the possibility of developing dependence even on so-called 'light' substances, and consequently the curiosity or need to reach for much potent and more destructive drugs $[16,17]$.

However, attention needs to be paid to other conditions that have been present and perpetuated for decades around the world, to a greater or lesser extent favoring the use of psychoactive substances, not yet included in national prevention strategies or ignored due to the scarcity of research on the impact of drugs on drug-related attitudes or for other reasons that are difficult to identify, which is particularly important to introduce prevention strategies different from the ones used so far in the post-pandemic reality, both oriented to new circumstances and affecting hitherto underestimated risk factors [18]. These postulates concern, in particular, the need to implement educational strategies (e.g., building a positive self-image, conflict resolution, interpersonal skills, coping with stress, assertiveness, and learning to accept mass media content critically) and strategies of implementing activities alternative to drug use (e.g., developing passions, interests, and health promotion).

This article aims to draw attention to the role of mass culture content in the possibility of liberalizing attitudes towards psychoactive substances and their use in recipients of such messages.

\section{Mass Culture and Its Impact}

Mass culture is a specific form of symbolic culture, and an essential feature of its characteristic message is the absence of direct contact between the sender and the receiver of the transmitted content. Mass culture carriers are all means of mass media (including cinema, television, radio, advertising, and magazines), but above all, the relevant aspect is the content presented in them [19]. The popularity and dissemination of this type of message are fostered by technological development, especially the availability of the internet, enabling the diffusion of all ideas to an unlimited group of recipients. The relationships that occur between the participants of virtual social networks create new patterns of interaction. These networks offer a platform for exchanging views and information in which there are hierarchies of roles (administrators and users) and provide strong group membership [20].

There are many examples in the scientific literature of online social networks having a positive impact on the health attitudes of participants in such interactions [21-23]. Unfortunately, many examples have also been identified of internet groups disseminating views that may consequently foster harmful or risky behaviors, including promoting violence 
and the use of psychoactive drugs [24-26]. Analogous examples of the influence of cultural texts on audience attitudes can be observed in other settings, e.g., listening to music containing messages about the use of psychoactive drugs can influence alcohol abuse, drug use, and aggressive behavior of fans of such music [27]. Inaccurate representations of drug use portrayed in films may also distort the image of this phenomenon [28]. Some studies suggest a causal relationship between watching such films and the risk behaviors observed in viewers of these messages $[29,30]$. Researchers have indicated the need for extensive research on such topics [31].

Interactions between members of different social groups are constantly changing. Considering the dynamics of society, it can be assumed that the relationships between behavior and cultural products can also change. Norms, principles, patterns of behavior are constantly being modeled. Some views and attitudes are accepted depending on culturally created positions, while others are criticized and rejected. Authors of social studies indicate that the products of contemporary mass culture may play an essential role in the liberalization of attitudes towards psychoactive drugs, presenting drugs as a sanction-free element of social life, free of odium, available, and almost unlimited [32-34]. The normative changes taking place in the modern world concerning narcotic drugs, the creation of a positive image of them in numerous media, and at the same time, the weakening of the role of the family and secularization processes have been recognized as crucial determinants of the changes in attitudes towards psychoactive drugs observed today [6,35-37]. Reaching for drugs with psychoactive properties may also be conditioned by the attitudes towards such drugs acquired from the external environment; for example, the perception of drugs as safe, intelligence-enhancing, and at the same time, accessible [38].

Contemporary mass media exert a strong influence on the recipients' behavior both in a planned and unplanned way. Educational actions carried out using mass communication media may be the source of accessible and reliable pro-health knowledge, and at the same time, they favor the modeling of behaviors expected by their senders [39]. At the same time, the same media may be a source of creating positive attitudes towards drugs and, as a result, drug use [40].

The scientific literature provides many theoretical concepts of the influence of mass media on the recipients of the exposed content, but we draw attention to two concepts in our considerations. The cultivation theory developed by George Gerbner and Larry Gross emphasizes the critical role of television as a medium reaching the widest audience, which by presenting a given social phenomenon often enough creates its perception among viewers. However, the reality shown on television is based more on speculation than facts [41]. According to Gerbner et al., the primary function of television is to perpetuate social patterns and cultivate resistance to change. The authors of the theory do not assume that frequent viewing of a given phenomenon will make us behave similarly to the characters of the watched broadcasts. However, frequent reception of certain behaviors cultivates and perpetuates the viewers' consciousness of their occurrence in the social space [42]. This theory has been developed based on several research projects in which the social effects of violence presented in the media were determined. However, its assumptions have also been adapted to the research on the attitudes towards alcohol in the recipients of music videos whose musicians presented an accessible approach to this issue [43], and research on the attitudes and sexual behavior of students cultivated by the activities observed in the characters of popular TV series [44]. Adapting the assumptions of this theory to the study of the reality related to the portrayal of drugs in the media, it can also be assumed that the frequent exposure of content depicting psychoactive drugs, especially in a casual or humorous emotional way, may favor liberalization of attitudes towards these drugs.

Albert Bandura's social learning theory also allows us to understand the modeling of media actors' attitudes on the recipients of these messages. According to the author of this theory, reaching for drugs is a consequence of adopting similar behavior patterns observed in persons significant for a given individual. The social learning theory identifies the causes responsible for deviant behavior and allows for a better understanding of it. By observing 
the behavior of essential people in his or her environment, the individual acquires and models these behaviors in himself or herself. Models are part of the social transmission of culture and are an essential social learning element [45]. Drug use observed in significant others or liberal attitudes towards this type of behavior can also be adopted. The group of models whose behaviors are imitated by youth includes mainly close family members, influential people in the peer environment, and youth idols, e.g., music band leaders. Observation plays an essential role in social learning, during which the frequency of observed behavioral patterns favors a more substantial impact on an individual. Remembering the observed activities, reproducing them, and, as a result, adopting them as one's own are the following stages of the learning process. Rewarding effects for accurate behavior imitation, including acceptance in a group, favor memorizing and faithful reproduction of observed behavior $[7,45]$. Strong associations with users of psychoactive substances significantly affect the imitation of this type of activity by individuals newly admitted to the community [46].

A tendency to act and behave similarly can be observed among recipients of mass culture content and a tendency to systematically become mass members of society who, imitating their idols, celebrities, and other people considered as authorities, duplicate the observed behaviors [47]. Technological progress, the emergence of new media, consumerism in its broadest sense, and incredibly persuasive and manipulative activities of the authors of mass-distributed content are among the many factors conducive to the standardization of messages and distortion of reality [48].

The cultivation and perpetuation of certain behaviors and the influence of broadly understood authority figures may be important factors favoring the spread of ideas liberalizing attitudes towards drugs.

\section{Representations of Drug Use in Mass Culture}

For several decades now, positive messages about psychoactive drugs have been frequent in mass culture productions. One can read about drugs or experiences related to their use in the press and books. There are films on the subject or films with drug themes. Music works on the subject, and internet portals created and maintained by people interested in drug-related issues almost freely present positions and experiences after drug use, as do some youth idols and celebrities [7]. In addition, representations of psychoactive drugs can be encountered while shopping, in grocery, clothing, drug or gadget shops, and on city streets, especially on buildings decorated with colorful pro-drug graffiti. Below is an overview of our observations.

\subsection{Feature Films}

Drug use has been a theme in the film industry for decades. Filmmakers often address both health-enhancing and risky behaviors, and at the same time, films with scenes of drug use have the potential to model behavior and convey normative propositions on issues such as unsafe sex and recreational drug use, among others [49].

Film productions with these themes began to appear as early as the fourth decade of the twentieth century, but at that time, they were more often concerned with alcohol dependence and the relationships shown between alcoholics and their relatives. In the last two decades of the twentieth century, many more films appeared in which drugs other than alcohol were used. Such scenes also began to form the main plot of screen adaptations [50]. Examples of films with frequent drug scenes include Trainspotting, Requiem for a Dream, Blue Collar, Easy rider, Big Lebowski, Drugstore cowboy, Bad Lieutenant, Traffic, Blow, Leaving Las Vegas, Kids, and many other film adaptations too numerous to list here [51,52]. The page 'List of drug-related films' can be found on Wikipedia, which contains an alphabetical list of several hundred films in which drug use is a significant theme or scenes of drug use or distribution. The drugs most frequently depicted in films are cocaine, heroin, cannabis, methamphetamines, and LSD [53]. 
Drug use is depicted in both films seen by international and national audiences, and film representations of drug use scenes may reflect the social image of drug use in a particular country, for example, Brazil [54], Scotland [31], Mexico, and Argentina [55]. In addition, many cinematic representations of drugs show a positive or neutral context of drug use, especially marijuana $[7,49]$.

Castaldelli-Maia et al. conducted a study to assess the representation of drug use in scenes from Oscar-nominated films between 2008 and 2011 [56]. The authors analyzed the media content of 47 films (nominated for Best Picture, Best Actor, and Best Actress) depicting drug use and/or its consequences. The researchers identified a total of 515 scenes of drug use in these films. Both alcohol, cigarette, and illicit drug use were presented as problematic or occasional behaviors, but usually in response to stress and tension. Moreover, an increase was observed annually in scenes of drug use other than alcohol and tobacco and scenes of simultaneous use of multiple drugs, including by women. According to the authors of the study, films with episodes of drug use reflect what is happening in society; in Western countries, more and more teenagers experiment with drugs, e.g., cannabis, while tobacco smoking is declining. At the same time, the researchers point out that Oscar-nominated films are among the most popular films and may influence the creation of behaviors of the recipients of this content [56].

In these films and others that feature scenes of drug use, the context of use and the phenomenon itself are not only presented neutrally or positively. Numerous productions with bleak depictions of family, relational and social dysfunction, such as Requiem for a Dream, are considered cult films in this genre. However, even in this dramatic film, which has been described as a 'horror film', the scenes of drug use can imply a desire for a drugged experience. Short sequences that vividly depict close-ups of drug packages being opened, preparation, drugs being ingested, distribution in the bloodstream, and pupils dilating after use can create an exciting need for the viewer to experience these states [57].

In addition, many positive or neutral representations of tobacco, alcohol, and drug use can be seen in contemporary film productions [7,49,54,55]. In earlier film adaptations of drug use scenes, such as the aforementioned Requiem for a Dream or Trainspotting, the message was relatively unambiguous and could inform future physicians about drug behavior and medical methods [51]; however, in these productions, some scenes, due to the attractive depiction of the moment of drug intake and colorful experiences, can also arouse interest in this mysterious and interestingly depicted activity.

Movies and shows available on digital streaming platforms, including Netflix, Hulu, HBOMax, and others, are top-rated, such as the 'Breaking Bad' series depicting methamphetamine use, also play an essential role in disseminating content that can foster a change in drug perceptions. According to Brian Braiker, methamphetamine has never had better marketing than in the 'Breaking Bad' series [58].

In April 2021, the third edition of the SPLIFF Film Festival took place online. As the originators of this project state: "SPLIFF is a place where filmmakers, artists, animators, and smokers share original short films that explore and (or) celebrate cannabis and its liberating effects on our imagination, appetites, libido and creative energy" [59].

\subsection{Music}

Messages in the text layer of musical works, in which their authors often directly popularize drug use, may play a similar role in the previously described representations of drug use in films. At the end of the twentieth century, it was warned that the musical preferences of adolescents might correlate positively with engaging in risky behaviors, such as reaching for drugs [60]. Analogous observations were reported by members of the Council on Communications and Media [61] at the end of the new millennium's first decade. Attention was paid primarily to representations of drug use in the lyrics of contemporary popular music.

In 2005, a content analysis of almost three hundred of the most popular songs (according to Billboard) was conducted to determine the frequency of drug-alcohol messages in 
the lyrics of selected music genres. The results of the study indicated that in pop songs, $9 \%$ of the content of this type was observed, in rock songs-14\%, in hip-hop and R\&B songs, $20 \%$ of the content about taking intoxicants was marked, and the highest indications were obtained in rap lyrics containing $77 \%$ of such messages. The authors of the study pointed out that music can be a reason for creating attitudes towards drugs. The measurement did not determine the impact of this type of content on youth behavior and focused solely on analyzing the text layer [62].

In addition, numerous other studies have observed associations of specific music genres (rap, reggae, techno, R\&B, punk, heavy metal, house, trance) with alcohol use [27,63-65], and drug use, including cannabis, amphetamine, ecstasy, LSD, hallucinogenic mushrooms, heroin and GHB $[27,63,65-70]$. In addition, information on music performers' CDs suggests that drugs are a fairly common theme, both visualized on the wrappers of the CDs and in their titles. Drugs are also sometimes cited as an inspiration for an album [70]. Studies have confirmed that the number of drug references in popular music lyrics has increased manifold in recent decades, while drug use is most often associated in these messages with splendor, wealth, mood enhancement, sexual activity, celebration, and social life [71-73].

Researchers on the relationship between music and behavior emphasize that even compositions without references to extra-musical reality can provoke strong psychological reactions in listeners [74], while texts transmitted through music can favor the popularization of the messages they contain [70]. Experiencing music is an experience of identity; the individual reacts to the piece being listened to and becomes involved in emotional alliances with the performers and other fans, creating a solid connection. The content heard can be absorbed and then adopted and brought into the listener's life as their own [75].

\subsection{Books, Specialist Magazines, Publications}

Publications published in the form of books are also an example of promoting drug use and encouraging this kind of activity. Among titles worth mentioning are: Food of the Gods and True Hallucinations by Terence McKenna revealing mysterious effects of narcotics, works by LSD discoverer Albert Hoffmann and authors such as Timothy Leary, Richard Alpert, and Ralph Metzner describing their drug experiments, and Daniel Pinchbeck, who in his book Breaking the Mind encourages to change the perception of psychoactive substances and to use their properties [7].

Books with a decidedly liberal attitude towards drugs are also published by the Polish publishing house 'Latawiec', which has published, among others, A. Hoffmann's work: LSD...my difficult child and a book entitled Marihuana: the first twelve thousand years, which is a study of this drug full of positive references. Similar items have been made available through other publishing houses distributing literature with a decidedly ambiguous message [7].

The dissemination of content saturated with positive information and messages about the use of psychoactive drugs is also exemplified by specialist magazines and publications aimed at those interested in psychoactive sensations, published by websites or available in paper form, including Soft Secret, Spliff-the Hemp Newspaper, which promotes the legalization of cannabis, and the attractively published magazine Trans/visions-Psychoactive Journal devoted to sensations after narcotics [7]. Obtaining such magazines is not difficult; they can be downloaded from websites, ordered by mail order, including archived issues, or encountered by chance as a promotional supplement to a book purchased from one of the publishing houses, as mentioned earlier.

The online platform feedspot.com updated in early April 2021, provides a ranking of 30 magazines publishing cannabis-related content to discuss cannabis news, companies, stocks, and technological advances, presenting the latest industry news, legal and financial information, business opportunities, cannabis compliance, among other topics. These publications also provide information on how to grow cannabis, strategies for growers and owners of finished product distribution businesses, current market data, and much more $[76,77]$. 


\subsection{Celebrities}

The glorification of drug use by celebrities and the prevalence of such behavior suggested by representatives of this group are further factors that may favor the liberalization of attitudes towards drugs [78]. Representatives of this group strongly influence the health behavior of their admirers, often turning them into followers of their preferred activities [79]. Projects have been undertaken in which researchers attempt to determine the impact of media coverage of idol drug use on adolescent behavior [80]. However, determining these relationships may not always be accurate as they may depend on the context in which the information is communicated; for example, reports of Amy Winehouse and Prince's drug-related deaths may negatively influence perceptions of drug use [80,81].

Research suggests that watching scenes in which actors, especially celebrities, use tobacco, alcohol, and other drugs, or discuss their use, may influence viewers' beliefs and behaviors regarding using these drugs. In a study among adolescents aged 12-15 years, it was found that smoking by film stars can play an essential role in encouraging adolescents, especially girls, to reproduce this behavior [82].

Sometimes depictions of psychoactive drug use are discussed and criticized by celebrities. However, sometimes the messages broadcast are inconsistent and create dissonance between the verbal and visual messages, as noted in analyses of a series depicting the life of rock star Ozzy Osbourne and his family [83]. Adolescents are a group particularly susceptible to such messages and quick to notice emerging differences and irregularities. At the same time, one has to consider irresponsible celebrities whose statements may pose serious health risks to their fans [84].

Studies conducted among adolescents have confirmed that despite the awareness of some pathological behaviors of their idols, adolescents unreflectively copy the activities observed in them. Along with the indifference and departure from previous authorities noticeable among adolescents, this phenomenon poses a considerable threat and challenge both to parents, teachers, and individuals or groups capable of influencing representatives of this age group. Celebrities admitting to using psychoactive substances may model such activity patterns among youth. For young people, idols are almost objects of worship, and at the same time, they are often mistakenly perceived as authorities. Unfortunately, they are often people who despise social norms, who have many problems and for whom using drugs is the norm, which they do not intend to hide [7].

\subsection{Internet}

Many researchers emphasize the vital role of social networking sites in the exchange of information among drug users. Many films, including on YouTube, depicting drug-related behavior can be found on the internet [85]. There are also portals on the internet created for everyone interested in drug use, e.g., Erowid, Bluelight [86], HipForums [87], Hyperreal, and Neurogroove [7]. In addition, popular social networks, e.g., Facebook, Twitter, and Instagram, are platforms often used for sharing drug experiences $[88,89]$. On these portals, it is possible to obtain all the information necessary for the home production of potent drugs produced from poppy seeds, over-the-counter (OTC) medicines combined with components available in every household, and information on all methods of achieving intoxication states [90,91]. Increasingly, drug traffickers are reaching out to young people through popular phone apps. In Denmark, Snapchat is the second (after Facebook) most popular virtual venue for drug trafficking. Dealers are ruthless and only care about getting new customers [92]. There are reports of deaths among even random teenage customers of drug dealers [93]. This knowledge can be obtained without any obstacles. As Paul M. Wax points out, it only takes one click to both obtain the information sought on drug use, its manufacture, 'safe' use and to purchase the goods sought via the internet [94].

The internet influences both the distribution and use of drugs; it facilitates the emergence of new producers and distributors in the global drug market while providing these actors with new customers and increasing demands for drugs [95]. 
In 2013, the EMCDDA identified 651 online sites offering new drugs, while in 2014, observation of emerging online offers confirmed the activity of portals offering other drugs for trade, previously only available on the so-called black market [96]. Acquisition of drugs is straightforward; after placing an order, a consignment is delivered to the indicated address within a few days, for which payment can be made only upon delivery. Traffickers often enhance standard consignments with free samples of new drugs. Attractive distribution and clear conditions set by online sellers create the appearance of legality, encouraging the use of the offered products [7].

In addition, there are quasi-pharmacies on the internet, where it is easy to purchase potent drugs without a prescription [97]. For more than a decade, an indeterminate number of shops offering Needle and Syringe Programs (NSP) and other drugs for trade have also been operating on the internet $[98,99]$.

Internet surveys conducted among NSP users confirm that Internet forums are the primary source of information on new drugs. After drug intoxication incidents, people who go to treatment centers admit that they have used the information posted, among others, on the Hyperreal website [7]. In addition, knowledge of NSP can be obtained from internet shops, dealers, friends, and the media. Other studies have also found that the main reason for using NSP was to come across positive accounts of drug use on Internet portals [100]. Organized drug trafficking via social media, including Instagram and Facebook, advertising drugs through these media, and the downplaying of the risks associated with their use is a problem systematically observed by law enforcement and public health agencies [101,102].

\subsection{Food}

For more than a decade, the food market has seen products infused with cannabinoids present, including tetrahydrocannabinol (THC). These products come in various forms, such as baked goods, sweets, or beverages. Countries where cannabis use has been legalized have taken the necessary regulatory steps to reduce the risk of intoxication by requiring edible products to have universal warning symbols, informing consumers of the correct serving size; limiting the amount of THC per serving and the total number of servings per item [103]. Unfortunately, poisonings of cannabis-based food products have been reported, even ending in user death [104]. However, in countries where the use of cannabis derivatives has been legalized, products labeled with a cannabis leaf can be purchased in regular grocery shops to attract the attention of those interested in using the drug [7]. In early 2021, 'BUH' beer was advertised as a product containing hemp extract (CBD) was and was mass-marketed in Poland. Although the content of hemp derivatives in alcohol was questioned and the information given was a clever marketing effort, the product aroused considerable interest among customers, and the producers intend to expand distribution to domestic small and large food shops [105]. Food products containing hemp derivatives are sometimes referred to as 'super foods' [106], and producers encourage purchase and consumption by creating new trends that adolescents can assimilate. The observation of consumer behavior of adolescents confirms the high popularity of these types of food products [107].

\subsection{Clothing, Jewellery, Gadgets, and Cosmetics}

Recent decades have seen a dynamic development of the clothing industry, which targets its products to specific consumer groups, including psychoactive drug users. It should be noted here that research on the worn clothing as a stimulus to undertake specific behaviors and clothing as self-expression and identification with a given social group confirm the occurrence of dependencies and links between these variables [108].

Clothing manufacturers offer various models of shirts, trousers, caps, sweatshirts, coats, socks, and other garments, both full of pop culture references and, of course, full of weed leaf prints containing messages glorifying the use of cannabis derivatives. Observers of this phenomenon believe that it is a developing trend and unstoppable $[109,110]$. Brands 
are emerging whose activities are directed towards producing both clothing and all gadgets related to the use of cannabis: decorative boxes, pipes, blotters, grinders, and other smoking utensils [111-113]. In addition, entire series of drug-related jewelry collections are being created, where earrings, rings, necklaces, bracelets, and other intricately crafted items offered are in the shape of cannabis leaves or other drugs [109,114], or necklace pendants shaped like the molecular structures of cocaine, methamphetamine, LSD, and other drugs [115].

Cosmetics drugstores are increasingly selling products decorated with hemp leaves. Even though they do not contain psychoactive substances in their composition, due to the social discourse related to the controversy over the legalization of marijuana, these products are also popular among consumers [116,117].

\section{Discussion}

Mass media can both promote pro-health culture and foster anti-health activities [118]. Many studies suggest that adolescents' risky behaviors are linked to exposure to drugliberal mass culture content depicted in film, music, literature, websites, and everyday products: food, clothing, cosmetics, and gadgets. Due to the growing number of studies conducted in establishing relationships between drug representations in mass culture and attitudes towards using these drugs, we present only a few.

A study that aimed to establish links between smoking scenes in films and nicotine initiation among adolescents viewing these films $(n=6522)$ found that viewing such scenes can activate smoking, and this behavior can then be followed up and conditioned by other factors, in particular, the immediate social context of smoking (e.g., growing up/being around smokers) and consequently nicotine dependence. However, the authors point out that these data should not be generalized [119].

A study that examined the influence of scenes of psychoactive drug use observed in the media on the use of such specifics found associations between these variables: respondents admitted that viewing mass media content with drug messages influenced their decision to use these drugs [40].

When analyzing posts available on Instagram about opioid abuse, the researchers observed that codeine misuse becomes commercialized and ritualized. Furthermore, these posts instruct and normalize this type of drug abuse while linking codeine use to pop culture icons (The Simpsons, Mickey Mouse, or Pokemon) in posts by appealing to humorous messages concerning dangers. At the same time, a frequent topic of discussion on Instagram was combining codeine with cannabis, alcohol, and benzodiazepines, which significantly increases the risk of consequences, including overdose mortality, especially among adolescents [89].

A 2011 study of US adolescents found that adolescents who regularly spend time on social networking sites are more likely to engage in risky behaviors, including smoking, alcohol consumption, and marijuana use. Researchers have attributed an essential role to social networking sites, including Facebook, Myspace, and others, where adolescents view photos of other users of the sites using psychoactive substances or view content on such sites that illustrate states experienced after drug use [120].

A study conducted among Polish adolescents $(n=2273)$ found statistically significant associations of listening to music, watching films, and browsing websites with liberal drug messages on attitudes towards drugs and increased indications of use reported by respondents [7].

The cited research data correspond to the cultivation theory of Gerbner and L. Gross [41], and the results of these studies suggest that the behavioral patterns shown in the media are perpetuated and nurtured, and transferred in the actions of the audience in the social space in which they function, learn, work, play, and live.

The ease of assimilating positions created by the lyrics of musical pieces or content present on Internet portals is strengthened by mutual interactions occurring, for example, during large-scale youth music shows. Therefore, these results correspond to the assump- 
tions of A. Bandura, indicating that drug use may be the result of taking over behavior patterns from persons significant for the individual [45].

The observed relations between the use of popular culture products and drug use also correspond to the features of social reality defined by the postmodern perspective: ambivalence, complete tolerance of all ideas, pluralism, liberalization, the aftermath of "modernity" defined by J. Baudrillard as "the state after the orgy"- the emergence of liberation in all possible spheres of social reality, including political liberation, sexual liberation, the liberation of women, children, unconscious drives, destructive powers, productive forces, and at the same time the affirmation of all models of representation and anti-representation [121].

However, to confirm both Baudrillard's suppositions and the considerations of the authors of this article, it is necessary to undertake well-designed research to precisely define these relational relationships [122].

\section{Conclusions}

The above data suggest an essential role of popular culture products (especially messages in contemporary music lyrics and content available on websites) in creating liberal, pro-drug positions. Other contents of popular culture which may influence drug use (e.g., films and books presenting drugs in a positive light and pro-drug declarations of famous and popular people admitting their experiences with drugs) are also of considerable importance.

The observations presented in this article consider only some of the many research issues related to this socially momentous phenomenon. The topic itself is a multidimensional, multifaceted problem. The material presented in this paper can be successfully used by practitioners (sociologists, pedagogues, and psychologists) and institutions focused on social prevention. It can also be a starting point for researching this critical social phenomenon. Suggested actions include:

- monitoring the representation of drug use in mass culture content;

- conducting reliable research on the impact of mass culture content on audiences;

- identify possible causal links between the use of such content and changes in attitudes towards and use of drugs;

- introducing preventive measures, including education on the critical reception of mass culture content.

Author Contributions: Conceptualization, M.A.M. and A.A.-I.; writing—original draft preparation, M.A.M.; writing-review and editing, A.A.-I. All authors have read and agreed to the published version of the manuscript.

Funding: This research received no external funding.

Institutional Review Board Statement: Not applicable.

Informed Consent Statement: Not applicable.

Data Availability Statement: Not applicable.

Conflicts of Interest: The authors declare no conflict of interest.

\section{References}

1. UNODC. World Drug Report 2020; United Nations Publication: Vienna, Italy, 2020.

2. EMCDDA. European Drug Report 2020: Trends and Developments; Publications Office of the European Union: Luxembourg, 2020.

3. Kaplow, J.B.; Curran, P.J.; Dodge, K.A. Conduct Problems Prevention Research Group. Child, parent, and peer predictors of early-onset substance use: A multisite longitudinal study. J. Abnorm. Child. Psychol. 2002, 30, 199-216. [CrossRef] [PubMed]

4. Frisher, M.; Crome, I.; Macleod, J.; Bloor, R.; Hickman, M. Predictive Factors for Illicit Drug Use among Young People: A Literature Review. Available online: http://dera.ioe.ac.uk/6903/1/rdsolr0507.pdf (accessed on 17 March 2021).

5. Chintalova-Dallas, R.; Case, P.; Kitsenko, N.; Lazzarini, Z. Boltushka: A homemade amphetamine-type stimulant and HIV risk in Odessa, Ukraine. Int. J. Drug Policy 2009, 20,347-351. [CrossRef] [PubMed]

6. Jiloha, R.C. Social and Cultural Aspects of Drug Abuse in Adolescents. Delhi Psychiatry J. 2009, 12, 167-175. 
7. Motyka, M.A. Socio-Cultural Determinants of Drug Addiction: The Scale and Causes of the Phenomenon among Young People in the Podkarpackie Province; Wydawnictwo UR: Rzeszow, Poland, 2018.

8. Di Trana, A.; Carlier, J.; Berretta, P.; Zaami, S.; Ricci, G. Consequences of COVID-19 Lockdown on the Misuse and Marketing of Addictive Substances and New Psychoactive Substances. Front. Psychiatry 2020, 11, 584462. [CrossRef]

9. Zaami, S.; Marinelli, E.; Varì, M.R. New Trends of Substance Abuse during COVID-19 Pandemic: An International Perspective. Front. Psychiatry 2020, 11, 700. [CrossRef]

10. Horigian, V.E.; Schmidt, R.D.; Feaster, D.J. Loneliness, Mental Health, and Substance Use among US Young Adults during COVID-19. J. Psychoact. Drugs 2021, 53, 1-9. [CrossRef]

11. Cranshaw, J. Covid-19: Blanket restrictions damage mental health. BMJ 2020, 371, m3913. [CrossRef]

12. Ornell, F.; Moura, H.F.; Scherer, J.N.; Pechansky, F.; Kessler, F.H.P.; von Diemen, L. The COVID-19 pandemic and its impact on substance use: Implications for prevention and treatment. Psychiatry Res. 2020, 289, 113096. [CrossRef]

13. Dos Santos, B.P.; de Gouveia, G.C.; Eller, S.; Pego, A.M.F.; Sebben, V.C.; de Oliveira, T.F. Is COVID-19 the current worldwide pandemic having effects on the profile of psychoactive substance poisonings? Forensic Toxicol. 2021, 39, 282-285. [CrossRef]

14. Dave, D.; Saffer, H. Demand for smokeless tobacco: Role of advertising. J. Health Econ. 2013, 32, 682-697. [CrossRef]

15. Bahreinifar, S.; Sheon, N.M.; Ling, P.M. Is snus the same as dip? Smokers' perceptions of new smokeless tobacco advertising. Tob. Control. 2013, 22, 84-90. [CrossRef] [PubMed]

16. Kandel, D.B. Does marijuana use cause the use of other drugs? JAMA 2003, 289, 482-483. [CrossRef]

17. Motyka, M.A. From energy drinks to drugs. New challenges of preventive policy. UR J. Humanit. Soc. Sci. 2019, 3, 139-158. [CrossRef]

18. Del Pozo, B.; Beletsky, L. No “back to normal" after COVID-19 for our failed drug policies. Int. J. Drug Policy 2020, 83, 102901. [CrossRef] [PubMed]

19. Dittmer, J. Popular Culture. In International Encyclopedia of Human Geography; Kitchin, R., Thrift, N., Eds.; Elsevier Science: Amsterdam, The Netherlands, 2009; pp. 269-273.

20. Roland, D.; Spurr, J.; Cabrera, D. Preliminary Evidence for the Emergence of a Health Care Online Community of Practice: Using a Netnographic Framework for Twitter Hashtag Analytics. J. Med. Internet Res. 2017, 19, e252. [CrossRef] [PubMed]

21. Gruzd, A.; Haythornthwaite, C. Enabling community through social media. J. Med. Internet Res. 2013, 15, e248. [CrossRef]

22. Hand, R.K.; Kenne, D.; Wolfram, T.M.; Abram, J.K.; Fleming, M. Assessing the Viability of Social Media for Disseminating Evidence-Based Nutrition Practice Guideline through Content Analysis of Twitter Messages and Health Professional Interviews: An Observational Study. J. Med. Internet Res. 2016, 18, e295. [CrossRef]

23. Schwenk, E.S.; Jaremko, K.M.; Park, B.H.; Stiegler, M.A.; Gamble, J.G.; Chu, L.F.; Utengen, A.; Mariano, E.R. I Tweet, Therefore I Learn: An Analysis of Twitter Use Across Anesthesiology Conferences. Anesth. Analg. 2020, 130, 333-340. [CrossRef] [PubMed]

24. Kazemi, D.M.; Borsari, B.; Levine, M.J.; Dooley, B. Systematic review of surveillance by social media platforms for illicit drug use. J. Public Health 2017, 39, 763-776. [CrossRef]

25. Malczewski, A.; Kidawa, M. New Psychoactive Substances in Europe. Scale of the Phenomenon and Prevention; Mazowieckie Centrum Polityki Społecznej: Warsaw, Poland, 2018.

26. Audrin, C.; Blaya, C. Psychological Well-Being in a Connected World: The Impact of Cybervictimization in Children's and Young People's Life in France. Front. Psychol. 2020, 11, 1427. [CrossRef] [PubMed]

27. Chen, M.J.; Miller, B.A.; Grube, J.W.; Waiters, E.D. Music, substance use, and aggression. J. Stud. Alcohol 2006, 67, 373-381. [CrossRef]

28. Iannicelli, P. Drugs in Cinema: Separating the Myths from Reality. UCLA Entertain. Law Rev. 2001, 9, 139-166. [CrossRef]

29. Sargent, J.D.; Beach, M.L.; Dalton, M.A.; Titus-Ernstoff, L.; Gibson, J.J.; Tickle, J.J.; Heatherton, T.F. Effect of parental R-rated movie restriction on adolescent smoking initiation. Pediatrics 2004, 114, 149-156. [CrossRef] [PubMed]

30. Dalton, M.A.; Sargent, J.D.; Beach, M.L.; Titus-Ernstoff, L.; Gibson, J.J.; Aherns, M.B.; Tickle, J.J.; Heatherton, T.F. Effect of viewing smoking in movies on adolescent smoking initiation: A cohort study. Lancet 2003, 362, 281-285. [CrossRef]

31. Hunt, K.; Sweeting, H.; Sargent, J.; Lewars, H.; Young, R.; West, P. Is there an association between seeing incidents of alcohol or drug use in films and young Scottish adults' own alcohol or drug use? A cross sectional study. BMC Public Health 2011, 11, 259. [CrossRef] [PubMed]

32. Hoffmann, B. Drugs in Youth Culture; Oficyna Wydawnicza Impuls: Krakow, Poland, 2014.

33. Jackson, K.M.; Janssen, T.; Gabrielli, J. Media/Marketing Influences on Adolescent and Young Adult Substance Abuse. Curr. Addict. Rep. 2018, 5, 146-157. [CrossRef]

34. Zakrzewski, T. Mechanisms of persuasion and advertising psychoactive drugs on the Internet Part IV. SI Narkom. 2009, 4, 33-37.

35. Brook, J.S.; Brook, D.W.; De La Rosa, M.; Whiteman, M.; Johnson, E.; Montoya, I. Adolescent Illegal Drug Use: The Impact of Personality, Family, and Environmental Factors. J. Behav. Med. 2001, 24, 183-203. [CrossRef] [PubMed]

36. Dalgalarrondo, P.; Soldera, M.A.; Corrêa Filho, H.R.; Silva, C.A.M. Religion and drug use by adolescents. Rev. Bras. Psiquiatr. 2004, 26, 82-90. [CrossRef]

37. Romer, D.; Moreno, M. Digital Media and Risks for Adolescent Substance Abuse and Problematic Gambling. Pediatrics 2017, 140 (Suppl. S2), S102-S106. [CrossRef]

38. Champagne, J.; Gardner, B.; Dommett, E.J. Modelling predictors of UK undergraduates' attitudes towards smart drugs. Trends Neurosci. Educ. 2019, 14, 33-39. [CrossRef] 
39. Dziukiewicz, J. Mass Media as a Space for the Creation of Health Behaviors in Society-Two Sides of the Same Coin. Media Społecz. 2018, 9, 127-142.

40. Odhiambo, O.D. Role of Mass Media on Prevalence of Illicit Drug Use among Public Secondary School Students in Kisumu. Int. J. Sci. Res. 2014, 3, 2491-2493.

41. Gerbner, G.; Gross, L.; Morgan, M.; Signorielli, N.; Shanahan, J. Growing up with television: Cultivation processes. In LEA's Communication Series. Media Effects: Advances in Theory and Research, 2nd ed.; Bryant, J., Zillmann, D., Eds.; Lawrence Erlbaum Associates Publishers: Mahwah, NJ, USA, 2002; pp. 43-67.

42. Russell, C.A.; Russell, D.W.; Boland, W.A.; Grube, J.W. Television's Cultivation of American Adolescents' Beliefs about Alcohol and the Moderating Role of Trait Reactance. J. Child Media 2014, 8, 5-22. [CrossRef]

43. Beullens, K.; Roe, K.; Van den Bulck, J. Music Video Viewing as a Marker of Driving After the Consumption of Alcohol. Subst. Use Misuse 2012, 47, 155-165. [CrossRef] [PubMed]

44. Bond, B.J.; Drogos, K.L. Sex on the Shore: Wishful Identification and Parasocial Relationships as Mediators in the Relationship between Jersey Shore Exposure and Emerging Adults' Sexual Attitudes and Behaviors. Media Psychol. 2014, 17, 102-126. [CrossRef]

45. Krohn, M.D.; Loughran, T.A.; Thornberry, T.P.; Jang, D.W.; Freeman-Gallant, A.; Castro, E.D. Explaining Adolescent Drug Use in Adjacent Generations: Testing the Generality of Theoretical Explanations. J. Drug Issues 2016, 46, 373-395. [CrossRef] [PubMed]

46. Goode, E. The Sociology of Drug Use. In 21st Century Sociology: A Reference Handbook; Bryant, D.C., Peck, L.D., Eds.; Sage Publication: Thousand Oaks, CA, USA, 2007; pp. 415-425.

47. Liu, Z. Relationship between Mass Media and Mass Culture: Frankfurt School and Cultural Studies School. Can. Soc. Sci. 2016, 12, 23-28. [CrossRef]

48. Wenderlich, P. Mass culture-active consumers, passive citizens? Implications in the public sphere. Świat Idei Polityki 2015, 14, 413-430.

49. Gunasekera, H.; Chapman, S.; Campbell. S. Sex and drugs in popular movies: An analysis of the top 200 films. J. R. Soc. Med. 2005, 98, 464-470. [CrossRef] [PubMed]

50. Osbourne, N. The Big List of Addiction \& Recovery Movies. Available online: https://recoveryfirst.org/blog/the-big-list-ofaddiction-recovery-movies / (accessed on 9 April 2021).

51. De Lacerda, A.P. Medical Education: Addiction and the Cinema (Drugs and gambling as a search for happiness). J. Med. Movies 2005, 1, 95-102.

52. Stern, S.; Morr, L. Portrayals of Teen Smoking, Drinking, and Drug Use in Recent Popular Movies. J. Health Commun. 2013, 18, 179-191. [CrossRef]

53. List of Drug Films. Available online: https://en.wikipedia.org/wiki/List_of_drug_films (accessed on 28 April 2021).

54. Castaldelli-Maia, J.M.; Bhugra, D.; de Andrade, A.G.; Lotufo-Neto, F. Substance use and misuse in Brazilian movies (2000-2008). Subst. Use Misuse 2013, 48, 248-257. [CrossRef]

55. Kollath-Cattano, C.; Abad-Vivero, E.N.; Mejia, R.; Perez-Hernandez, R.; Sargent, J.D.; Thrasher, J.F. Portrayals of character smoking and drinking in Argentine-, Mexican- and US-produced films. Prev. Med. 2016, 90, 143-147. [CrossRef] [PubMed]

56. Castaldelli-Maia, J.M.; Gil, F.; Ventriglio, A.; Torales, J.; Florio, L.; Moura, H.F.; de Andrade, A.G.; Lotufo-Neto, F.; Bhugra, D. Substance Use Portrayal in Oscar-nominated Movies. Curr. Drug Res. Rev. 2020. [CrossRef] [PubMed]

57. Grist, L. Drugs, the family and recent American cinema. In Drugs and Popular Culture. Drugs, Media and Identity in Contemporary Society; Manning, P., Ed.; Willan Publishing: Cullompton, UK, 2007; pp. 117-133.

58. Braiker, B. Was 'Breaking Bad' Good for the Meth Business? Available online: https://digiday.com/marketing/breaking-badmarketing-meth/ (accessed on 25 May 2021).

59. 2021 SPLIFF Film Festival. Available online: https:// btt.boldtypetickets.com/111027771/2021-spliff-film-festival (accessed on 27 April 2021).

60. Committee on Communications. Impact of Music Lyrics and Music Videos on Children and Youth (RE9144). Pediatrics 1996, 98, 1219-1221.

61. Council on Communications and Media. Impact of Music, Music Lyrics, and Music Videos on Children and Youth. Pediatrics 2009, 124, 1488-1494. [CrossRef]

62. Primack, B.A.; Dalton, M.A.; Carroll, M.V.; Agarwal, A.A.; Fine, M.A. Content Analysis of Tobacco, Alcohol, and Other Drugs in Popular Music. Arch. Pediatr. Adolesc. Med. 2008, 162, 169-175. [CrossRef]

63. Adlaf, E.M.; Smart, R.G. Party Subculture or Dens of Doom? An Epidemiological Study of Rave Attendance and Drug Use Patterns Among Adolescent Students. J. Psychoact. Drugs 1997, 29, 193-198. [CrossRef]

64. Mulder, J.; Ter Bogt, T.; Raaijmakers, Q.; Gabhainn, S.; Monshouwer, K.; Vollebergh, W. The Soundtrack of Substance Use: Music Preference and Adolescent Smoking and Drinking. Subst. Use Misuse 2009, 44, 514-531. [CrossRef]

65. Vuolo, M.; Uggen, C.; Lageson, S. Taste clusters of music and drugs: Evidence from three analytic levels. Br. J. Sociol. 2014, 65, 529-554. [CrossRef]

66. Forsyth, A.J. Places and patterns of drug use in the Scottish dance scene. Addiction 1996, 91, 511-521. [CrossRef]

67. Ter Bogt, T.F.M.; Engels, R.C.M.E. "Partying" Hard: Party Style, Motives for and Effects of MDMA Use at Rave Parties. Subst. Use Misuse 2005, 40, 1479-1502. [CrossRef]

68. Salasuo, M.; Seppälä, P. The party scene of Helsinki. Nord. Stud. Alcohol Dr. 2005, 22 (Suppl. S1), 142-145. [CrossRef] 
69. Fernández-Calderón, F.; Cleland, C.M.; Palamar, J.J. Polysubstance Use Profiles Among Electronic Dance Music Party Attendees in New York City and Their Relation to Use of New Psychoactive Substances. Addict. Behav. 2018, 78, 85-93. [CrossRef]

70. Motyka, M.A.; Al-Imam, A. Musical preference and drug use among youth: An empirical study. Res. Adv. Psychiatr. 2019, 6, 50-57.

71. Herd, D. Changes in drug use prevalence in rap music songs, 1979-1997. Addict. Res. Theory 2008, 16, 167-180. [CrossRef]

72. Christenson, P.; Roberts, D.F.; Bjork, N. Booze, Drugs, and Pop Music: Trends in Substance Portrayals in the Billboard Top 100-1968-2008. Subst. Use Misuse 2012, 47, 121-129. [CrossRef]

73. Hall, P.C.; West, J.H.; Neeley, S. Alcohol, tobacco, and other drug references in lyrics of popular music from 1959 to 2009. Addict. Res. Theory 2013, 21, 207-215. [CrossRef]

74. Antovic, M. Towards a Semantics of Music-the 20th century. Lang. Hist. 2009, 52, 119-129. [CrossRef]

75. Frith, S. Music and identity. In Questions of Cultural Identity; Hall, S., Du Gay, P., Eds.; Sage Publications Ltd: London, UK, 2011; pp. 108-127. [CrossRef]

76. Feedspot. Top 30 Cannabis and CBD Magazines \& Publications to Follow in 2021. Available online: https://blog.feedspot.com/ cbd_magazines/ (accessed on 16 April 2021).

77. Ganjapreneur. Cannabis Magazines \& Publications. Available online: https://www.ganjapreneur.com/cannabis-publications/ (accessed on 16 April 2021).

78. Costello, C.R.; Ramo, D.E. Social Media and Substance Use: What Should We Be Recommending to Teens and Their Parents? J. Adolesc. Health 2017, 60, 629-630. [CrossRef]

79. Just, J.M.; Bleckwenn, M.; Schnakenberg, R.; Skatulla, P.; Weckbecker, K. Drug-related celebrity deaths: A cross-sectional study. Subst. Abuse Treat. Prev. Policy 2016, 11, 40. [CrossRef]

80. Shaw, R.L.; Whitehead, C.; Giles, D.C. "Crack down on celebrity junkies": Does media coverage of celebrity drug use pose a risk to young people? Health Risk Soc. 2010, 12, 575-589. [CrossRef]

81. Levy, L. These Are the Drugs Influencing Pop Culture Now. Available online: https://www.vulture.com/2018/02/the-drugsinfluencing-pop-culture-right-now.html (accessed on 14 March 2021).

82. Distefan, J.M.; Pierce, J.P.; Gilpin, E.A. Do favorite movie stars influence adolescent smoking initiation? Am. J. Public Health 2004, 94, 1239-1244. [CrossRef]

83. Blair, N.A.; Yue, S.K.; Singh, R.; Bernhardt, J.M. Depictions of substance use in reality television: A content analysis of The Osbournes. BMJ 2005, 331, 1517-1519. [CrossRef]

84. Neill, U.S. Tom Cruise is dangerous and irresponsible. J. Clin. Investig. 2005, 115, 1964-1965. [CrossRef]

85. Manning, P. YouTube, 'drug videos' and drugs education. Drugs Educ. Prev. Pol. 2013, 20, 120-130. [CrossRef]

86. Bell, V. Cultures of chemically induced hallucinations. Psychologist 2014, 27, 666-668.

87. Gabbriellini, S. The Evolution of Online Forums as Communication Networks: An Agent-Based Model. Rev. Française Sociol. 2014, 55, 805-826. [CrossRef]

88. Moreno, M.A.; Whitehill, J.M. Influence of Social Media on Alcohol Use in Adolescents and Young Adults. Alcohol Res. 2014, 36, 91-100.

89. Cherian, R.; Westbrook, M.; Ramo, D.; Sarkar, U. Representations of Codeine Misuse on Instagram: Content Analysis. JMIR Public Health Surveill. 2018, 4, e22. [CrossRef]

90. Cinosi, E.; Corazza, O.; Santacroce, R.; Lupi, M.; Acciavatti, T.; Martinotti, G.; di Giannantonio, M. New drugs on the Internet: The case of Camfetamine. Biomed. Res. Int. 2014, 419026. [CrossRef]

91. Hearne, E.; Grund, J.-P.C.; Van Hout, M.C.; McVeight, J. A scoping review of home-produced heroin and amphetamine-type stimulant substitutes: Implications for prevention, treatment, and policy. Harm Reduct. J. 2016, 13, 14. [CrossRef]

92. Demant, J.; Bakken, S.A.; Oksanen, A.; Gunnlaugsson, H. Drug dealing on Facebook, Snapchat and Instagram: A qualitative analysis of novel drug markets in the Nordic countries. Drug Alcohol Rev. 2019, 38, 377-385. [CrossRef]

93. Abrahamson, R.P. Mom Warns about Drug Dealers on Snapchat after Son, 16, Dies from Overdose. Available online: https: / / www.today.com/parents/dr-laura-berman-s-son-dies-bought-drugs-snapchat-t208352 (accessed on 25 May 2021).

94. Wax, P.M. Just a Click Away: Recreational Drug Web Sites on the Internet. Pediatrics 2002, 109, e96. [CrossRef]

95. Birdwell, J.; Chapman, J.; Singleton, N. Taking Drugs Seriously: A Demos and UK Drug Policy Commission Report on Legal Highs; Demos Pub.: London, UK, 2011.

96. EMCDDA. European Drug Report 2016: Trends and Developments; Publications Office of the European Union: Luxembourg, 2016.

97. Jena, A.B.; Goldman, D.P. Growing Internet use may help explain the rise in prescription drug abuse in the United States. Health Aff. 2011, 30, 1192-1199. [CrossRef]

98. Mounteney, J.; Cunningham, A.; Groshkova, T.; Sedefov, R.; Griffiths, P. Looking to the future-more concern than optimism that cryptomarkets will reduce drug-related harms. Addiction 2018, 113, 799-800. [CrossRef]

99. Van der Gouwe, D.; Brunt, T.M.; Van Lear, M.; Van der Pol, P. Purity, adulteration and price of drugs bought online versus off-line in the Netherlands. Addiction 2017, 112, 640-648. [CrossRef]

100. Soussan, C.; Andersson, M.; Kjellgren, A. The diverse reasons for using Novel Psychoactive Substances-A qualitative study of the users' own perspectives. Int. J. Drug Policy 2018, 52, 71-78. [CrossRef]

101. Yang, X.; Luo, J. Tracking Illicit Drug Dealing and Abuse on Instagram Using Multimodal Analysis. ACM Trans. Intell. Syst. Technol. 2017, 8, 58. [CrossRef] 
102. Miliano, C.; Margiani, G.; Fattore, L.; De Luca, M.A. Sales and Advertising Channels of New Psychoactive Substances (NPS): Internet, Social Networks, and Smartphone Apps. Brain Sci. 2018, 8, 123. [CrossRef]

103. Borodovsky, J.T.; Budney, A.J. Legal cannabis laws, home cultivation, and use of edible cannabis products: A growing relationship? Int. J. Drug Policy 2017, 50, 102-110. [CrossRef]

104. Hancock-Allen, J.B.; Barker, L.; Van Dyke, M.; Holmes, D.B. Notes from the Field: Death Following Ingestion of an Edible Marijuana Product-Colorado, March 2014. MMWR Morb. Mortal. Wkly. Rep. 2015, 64, 771-772. [CrossRef] [PubMed]

105. Żabka Offers Beer from Kuba Wojewódzki and Janusz Palikot. Available online: https://ding.pl/blog/artykuly/zabka-oferujepiwo-od-kuby-wojewodzkiego-i-janusza-palikota,1529 (accessed on 20 April 2021).

106. Simonsohn, B. Super Food Hanf. Protein Miracle and Remedy; Schirner Verlag: Darmstadt, Germany, 2016.

107. Roberts, C. Million Dollar Cookie: How Berner Built a Business Empire on Marijuana. Available online: https:/ / www.sfweekly. $\mathrm{com} /$ news/million-dollar-cookie-how-berner-built-a-business-empire-on-marijuana/ (accessed on 28 April 2021).

108. Johnson, K.; Lennon, S.J.; Rudd, N. Dress, body and self: Research in the social psychology of dress. Fash. Text. 2014, 1, 1-24. [CrossRef]

109. Agnew, C. Marijuana in Fashion: How Cannabis Became a Recurring Trend in the Industry. Available online: https:// fashionmagazine.com/style/marijuana-fashion-trend/ (accessed on 28 April 2021).

110. Weed and Fashion: An Unstoppable Trend. Available online: https://www.royalqueenseeds.com/blog-weed-and-fashion-anunstoppable-trend-n553 (accessed on 28 April 2021).

111. Moor, K. Cannabis Branding: 42 Chronic Weed Logos and Marijuana Packaging Ideas. Available online: https:/ /99designs.com/ blog/creative-inspiration/cannabis-branding-weed-logos-marijuana-packaging-ideas/ (accessed on 25 April 2021).

112. Nolan, A. Weed Apparel and Streetwear Brands for Stoners with Style. Available online: https://weedmaps.com/news/2019/0 7/weed-apparel-and-streetwear-brands-for-stoners-with-style/ (accessed on 26 April 2021).

113. Han, G. 4/20 Flower Power: The Colorful Design of Cannabis. Available online: https:/ / design-milk.com/4-20-flower-powerthe-colorful-design-of-cannabis/ (accessed on 25 April 2021).

114. Gomelsky, V. Marijuana Motifs Go From Hippie to High (Jewelry, That Is). Available online: https://www.nytimes.com/2019/0 3/22/fashion/jewelry-marijuana-motifs.html (accessed on 11 March 2021).

115. Dunne, C. A Line of Jewelry Inspired by Illicit Drugs. Available online: https://www.fastcompany.com/3023085/a-line-ofjewelry-inspired-by-illicit-drugs (accessed on 14 April 2021).

116. Studeman, K.T. High Fashion: How the Legal Weed Industry Is Becoming More Stylish. Available online: https://www.vogue. com/article/high-fashion-legal-weed-industry-is-becoming-more-stylish (accessed on 28 April 2021).

117. Przybylak, Z.; Kordus, K. People awareness of the use of hemp oil. Kosmetol. Est. 2018, 4, 393-396.

118. Dutta, M.J. Content Effects: Personal and Public Health. In The International Encyclopedia of Media Effects; Rössler, P., Hoffner, C.A., Zoonen, L., Eds.; John Wiley \& Sons: Hoboken, NJ, USA, 2017; pp. 1-14. [CrossRef]

119. Dal Cin, S.; Stoolmiller, M.; Sargent, J.D. When movies matter: Exposure to smoking in movies and changes in smoking behavior. J. Health Commun. 2012, 17, 76-89. [CrossRef]

120. 2011 National Teen Survey Finds: Teens Regularly Using Social Networking Sites Likelier to Smoke, Drink, Use Drugs. Available online: https:/ / www.prnewswire.com/news-releases/2011-national-teen-survey-finds-teens-regularly-using-socialnetworking-sites-likelier-to-smoke-drink-use-drugs-128295633.html (accessed on 28 April 2021).

121. Baudrillard, J. The Transparency of Evil: Essays on Extreme Phenomena; Verso: London, UK, 1993.

122. Al-Imam, A.; Motyka, M.A. On the Necessity for Paradigm Shift in Psychoactive Substances Research: The Implementation of Machine Learning and Artificial Intelligence. Alcohol. Drug Addict. 2019, 32, 237-242. [CrossRef] 